\title{
EDITORIAL
}

\section{One World (Not Three)}

I was a mere babe-in-arms when my parents dragged my brothers and me across an ocean and most of a continent to settle in Canada. Once, being an immigrant meant staring open-mouthed at the ESL teacher and mailing birthday cards that took three months to arrive. Now, it means heated, multilingual video-debating with relatives half a world away as all involved watch the same live newscast about events in a third place altogether.

With continual improvements in the affordability and convenience of international travel, trade, and information exchange, stories like mine are becoming more commonplace and monikers like "global village" are becoming increasingly apt for describing the world. Modern telecommunications and transport are progressively overcoming the challenges posed by physical separation, bringing the rest of the world quite literally closer to home.

Still, geography continues to matter and stories vastly unlike mine remain the norm. The International Telecommunications Union estimates, for example, that $77 \%$ of the developed world is connected to the Internet while only $31 \%$ of the developing world can say the same. Accordingly, the WHO finds that low income countries contend with twice the number of disability-adjusted life-years per capita than high income countries do. Clearly, people and ideas might be moving faster, but they're not reaching many parts of the world that are in need. In this issue of the UWOMJ, we explore some of the causes and consequences of these disparities, both in Canada and abroad.

Some of our contributors, inspired by personal interest and experiences abroad, choose to explore the challenges of medical provision in locales and through systems different from our own. These run the gamut from the everyday headaches of providing safe and cost-effective nutrition, surgery, and diagnostics to the difficulties of managing oncein-a-lifetime infectious disease or natural disaster crises.
Other contributors discuss the proper way to manage Canadian healthcare, given its global context.

Overwhelmingly, the message is that one size does not fit all: refugees and other newcomers are deserving and in need of aid, and complementary and alternative medicines popularized by cultural practices merit individual consideration.

The stories told in this issue hail from all over the world, many in places far from here, but as Sting would have us know, that all "gets a little closer every day." The health and well-being of those living on the other side of the world do and should matter to us. So, for less than the price of a bus fare to the airport, let the UWOMJ take you on a highlights tour of the global healthcare landscape.

\section{Anthony Chow}

Senior Associate Editor 